\title{
Development of Anhydrous Ethanol Purification: Reduction of Acetal Content and Vapor-Liquid Equilibrium Study of the Ethanol-Acetal Binary System
}

\author{
Eniko Haaz, Daniel Fozer, and Andras Jozsef Toth*
}

Cite This: ACS Omega 2021, 6, 1289-1298

Read Online

ABSTRACT: Acetaldehyde diethyl acetal (herein called acetal) is an important pollutant of anhydrous ethanol. Isobaric vapor-liquid equilibrium (VLE) of an ethanol-acetal binary system was measured using a vapor condensate and liquid circulation VLE still. The experimental data were correlated with Wilson, nonrandom twoliquid (NRTL), and universal quasichemical (UNIQUAC) activity coefficient models, which were found suitable for representing the VLE data. Proper agreements between experimental and calculated VLE data were obtained, which were then confirmed with consistency tests. The applicability of the novel VLE data was demonstrated during an investigation of an anhydrous ethanol purification column.

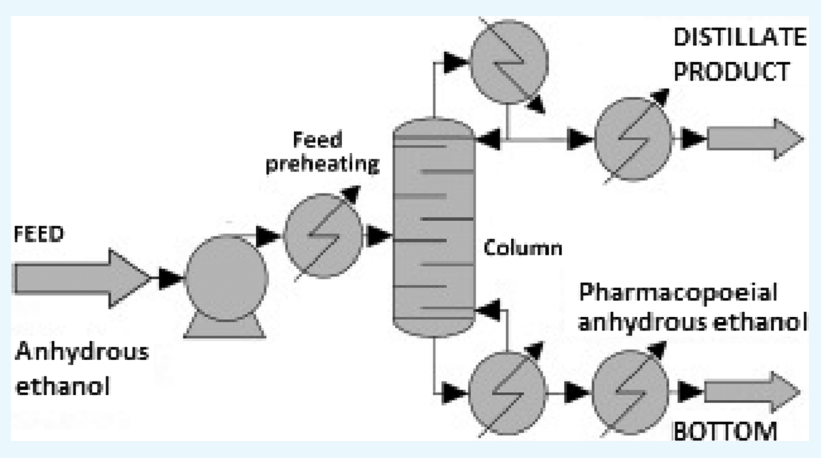
Reduction of the concentration of acetal and other pollutants was examined and optimized in a flowsheet environment. The modeling results were verified in a laboratory with an experimental distillation column, confirming a correct agreement between the results. It must be highlighted that the developed method is suitable for the production of pharmacopeial quality anhydrous alcohol, based on reliable, verified VLE data. The results show the importance of accurate VLE data in critical compositions (low pollutant content); moreover, aiming at high product purity, experimental validation has paramount importance. The consistency between the three platforms (VLE and distillation experiments and flowsheet simulation) confirms the accuracy of the developed method.

\section{INTRODUCTION}

Certain industries, for example, pharmaceutical and fine chemical sectors, need high purity chemicals. Such chemicals are frequently produced by distillation. In the case of pharmacopeial anhydrous alcohol, there are strict requirements regarding polluting compounds. For the reliable production of such ethanol, a proper process should be designed. Nowadays, the process design activities are strongly based on professional flowsheeting software programs. These software programs must operate on a reliable database, rigorous modeling tools, and accurate calculation based on thermodynamic equilibria. The accuracy of these tools is generally sufficient; however, in a research focused on obtaining high purity chemicals, special attention must be paid to the evaluation of the computed results.

A typical example for the application of distillation is the production of ethanol, as a precious chemical in fine chemical industry. ${ }^{1}$ Basically, ethanol production is performed through a biological process, resulting in bioethanol, obtained in different qualities/purities depending on its application. ${ }^{2-5}$

Anhydrous ethanol has an alcohol content of at least $99.7 \mathrm{v} / \mathrm{v}$ $\%$ and thus an extremely low water content. ${ }^{6}$ The extremely low water content makes it suitable for use by fuel manufacturers to make mixed fuel. ${ }^{7}$ By mixing with traditional petrol in fuel production, the proportion of biocomponents has increased, thus reducing traffic emissions of environmentally harmful greenhouse gases. $^{8-10}$ Pharmacopeial anhydrous alcohol is a premium quality anhydrous alcohol which, besides conforming to the relevant EU and Hungarian specifications, also meets the strict requirements of the PHHg VIII, EU Pharma 4 pharmacopeial regulations. ${ }^{11,12}$ The major aim of this work is to develop the conversion process from anhydrous ethanol produced on a biological source to pharmacopeial anhydrous alcohol using distillation.

The required level of purity is extremely difficult to achieve as raw anhydrous alcohol contains a wide variety of contaminants, albeit only in small concentrations. Examples of ethanol contaminants include acetal, acetaldehyde, acetone, benzene, cyclohexane, methanol, ethyl methyl ketone, isobutyl methyl ketone, propanol, isopropyl alcohol, butanols, furfural, 2methylpropan-2-ol, and 2-methylbutan-2-ol. ${ }^{13}$ During the distillation process, polluting compounds have to be removed

Received: September 28, 2020

Accepted: December 23, 2020

Published: January 5, 2021 
to obtain the high purity bottom product, considered pharmacopeial anhydrous alcohol.

One of the most important pollutant compounds is acetal, as it belongs to the most common contaminants. Acetaldehyde diethyl acetal (1,1-diethoxyethane) is a major flavoring component of distilled beverages, especially of sherry ${ }^{14}$ and malt whisky. ${ }^{15}$ In spite of being one of many compounds containing the acetal functional group, this specific chemical is often simply referred to as acetal.

Acetal is applied in the design of synthetic perfumes to increase the resistance to oxidation, therefore the lifetime of perfumes. Acetals have been under consideration as oxygenated additives to diesel fuel because they drastically decrease the emission of nitrogen oxides and other particles while retaining or improving the cetane number and helping in the combustion of the final products, without decreasing the ignition quality. ${ }^{16-19}$

1,1-Diethoxyethane production involves the reversible reaction of acetaldehyde and ethanol in acid medium, according to the following: acetaldehyde +2 ethanol $\leftrightarrow$ acetal + water (see Figure 1). ${ }^{20-22}$ However, acetaldehyde could be replaced by

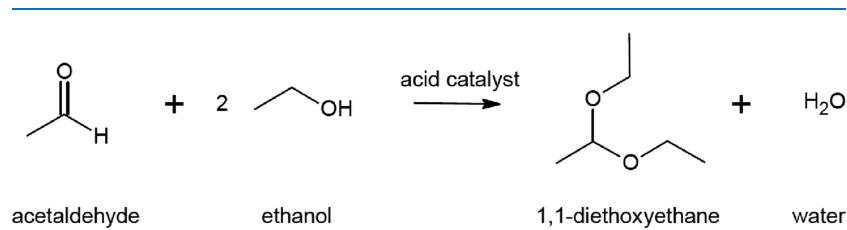

Figure 1. Acetalization of acetaldehyde and ethanol.

ethylene, acetylene, or vinyl ether. ${ }^{23}$ The advantage of using acetaldehyde and ethanol as reactants is that ethanol is produced from renewable sources (mainly from the sugarcane industry) and acetaldehyde can be produced by dehydrogenation of ethanol or direct ethylene oxidation. ${ }^{19,24,25}$

The reaction shown in Figure 1 is slightly exothermic; at a temperature of $25{ }^{\circ} \mathrm{C}$, a $59 \%$ conversion can be achieved with a sulfonic acid catalyst. The acetal formed can be used as an additive to diesel fuels as it increases the cetane number and promotes combustion of the mixture. ${ }^{26}$

In order to increase the purification efficiency, it is essential to know the exact vapor-liquid phase equilibrium data of the mixture. Ionescu et al. ${ }^{27}$ have presented the vapor-liquid equilibrium (VLE) data and nonrandom two-liquid (NRTL), Wilson, and Gothard model parameters of ethanol-diethyl acetate and i-propanol-diethyl acetate binary mixtures. In contrast, the VLE data and main thermodynamic models for other contaminant components of anhydrous ethanol have already been explored in detail. ${ }^{28,29}$ Consequently, a further goal of this work is to experimentally determine the VLE data of this binary mixture for universal quasichemical (UNIQUAC) model parameters too and to verify the VLE data with laboratory distillation experiments and in a flowsheet environment.

The purpose of VLE analysis is to determine equilibriumrelated data and the boiling-dew point, in addition to thermodynamic data. Today, these can be calculated with fairly high accuracy using process simulators, various state equations, and activity coefficient models, but the basis of the calculations lies in the knowledge of reliable and accurate measurement data and physicochemical parameters. It is not possible to perform accurate calculations with thermodynamic relations alone, as it requires knowledge of appropriate measurement data and parameters derived from them.
These can be used to explore the possible azeotropic behavior of liquid mixtures; furthermore, separation possibilities of liquid mixtures can also be modeled on the basis of this data. Simulation programs often determine the state of a multicomponent mixture from the parameters of the pure components, which can cause discrepancies with their actual behavior. For example, they show an azeotrope, or a liquidliquid distribution, where it does not actually occur, or they do not reveal it where it is in fact present. However, knowledge of azeotropes is essential in the design of a separation unit, as they require different technologies and special design considerations.

VLE data and the resulting pair interaction parameters can be used to model the separation of different mixtures, as well as for the design of separation systems. In the context of industrial implementation, the economic aspects are also taken into account in which case different separation models can also be used for cost calculation.

During the measurements, it is necessary to examine the equilibrium phases of vapor and liquid under the same conditions. VLE points can be determined in two ways. Either the operation is carried out at constant temperature and the pressure is changed point by point or vice versa. By these means, it is possible to perform isothermal or isobaric measurements.

Since the vast majority of columns in industrial separation units operate under constant pressure, in the present work, the vapor-liquid phase equilibrium of the various mixtures is also measured at constant pressure.

However, the measurement data must be examined to determine whether they are in accordance with the relevant thermodynamic laws, for which the so-called thermodynamic consistency tests, derived from thermodynamic relationships, are used. ${ }^{30}$ Thermodynamic theorems provide a deeper understanding of different physical, physicochemical, and thermal processes. The equations derived from these are still used today to quantitatively describe chemical systems and phase equilibria. In order to make sure that the measured data comply with the laws of thermodynamics, consistency tests can serve as a tool for verification. ${ }^{31}$ It is important to check if the measured equilibria correspond to reality, that is, whether the measurement points are consistent or inconsistent. ${ }^{32,33}$ If they are shown to be consistent, they meet the thermodynamic theorems and the data set can be considered reliable.

\section{RESULTS AND DISCUSSION}

First, the modified equipment and VLE measurement procedure were tested with the acetaldehyde-ethanol binary mixture as a well-known and studied system. Good reproducibility and correlation with published results were obtained for the VLE data $^{29}$ at $101 \mathrm{kPa}$ (Supporting Information: Table S1, Figures S1 and S2). It can be stated that the equilibrium still was suitable for measurements.

The refractive indexes were experimentally determined in the whole concentration range for the ethanol (1)-acetal (2) system at $T=293.2 \mathrm{~K}$. The data are shown in Table 1 . The concentration versus refractive index plots are shown in Figure 2.

The isobaric VLE of ethanol (1)-acetal (2) was measured at $p$ $=101 \mathrm{kPa}$. With the experimental data, NRTL, Wilson, and UNIQAC parameters were regressed. The experimental and calculated data are presented in Table 2 and Figures 3 and 4 . The activity coefficients presented were calculated by eq 1 . 
Table 1. Experimental Refractive Indexes $\left(n_{\mathrm{D}}\right)$ of the Ethanol (1)-Acetal (2) Mixture at $293.2 \mathrm{~K}, p=101 \mathrm{kPa}^{a}$

\begin{tabular}{|c|c|c|c|c|c|}
\hline \multicolumn{2}{|c|}{ ethanol content } & \multirow{2}{*}{$\frac{n_{\mathrm{D}}[-]}{(293.15 \mathrm{~K})}$} & \multicolumn{2}{|c|}{ ethanol content } & \multirow{2}{*}{$\frac{n_{\mathrm{D}}[-]}{(293.15 \mathrm{~K})}$} \\
\hline$[\mathrm{mol} / \mathrm{mol}]$ & {$[\mathrm{g} / \mathrm{g}]$} & & {$[\mathrm{mol} / \mathrm{mol}]$} & {$[\mathrm{g} / \mathrm{g}]$} & \\
\hline 0.0000 & 0.0000 & 1.3805 & 0.5527 & 0.3251 & 1.3753 \\
\hline 0.0180 & 0.0071 & 1.3805 & 0.5964 & 0.3655 & 1.3747 \\
\hline 0.0485 & 0.0195 & 1.3802 & 0.6461 & 0.4158 & 1.3737 \\
\hline 0.0976 & 0.0405 & 1.3800 & 0.6867 & 0.4608 & 1.3727 \\
\hline 0.1521 & 0.0654 & 1.3798 & 0.7509 & 0.5402 & 1.3711 \\
\hline 0.2104 & 0.0941 & 1.3795 & 0.8014 & 0.6114 & 1.3697 \\
\hline 0.2477 & 0.1138 & 1.3790 & 0.8437 & 0.6779 & 1.3682 \\
\hline 0.3092 & 0.1486 & 1.3786 & 0.8995 & 0.7773 & 1.3660 \\
\hline 0.3510 & 0.1741 & 1.3782 & 0.9520 & 0.8855 & 1.3647 \\
\hline 0.4009 & 0.2069 & 1.3775 & 0.9898 & 0.9743 & 1.3615 \\
\hline 0.4598 & 0.2491 & 1.3767 & 1.0000 & 1.0000 & 1.3611 \\
\hline 0.5044 & 0.2840 & 1.3760 & & & \\
\hline
\end{tabular}

${ }^{a}$ Standard uncertainty $u$ is $u\left(n_{\mathrm{D}}\right)=0.0001, u(p)=2 \mathrm{kPa}, u(T)=0.1$ $\mathrm{K} ; u\left(x_{1}\right)=0.0001$.

$$
\gamma_{i}=\frac{y_{i} \times p}{x_{i} \times p_{i}^{*}}
$$

The minimization of ChemCAD's objective function was utilized to obtain model parameters ${ }^{34}$ with eq 2 .

$$
\mathrm{OF}_{\mathrm{VLE}}=\sum_{i=1}^{N}\left(y_{\mathrm{exp}, i}-y_{\mathrm{cal}, i}\right)^{2}+\sum_{i=1}^{N}\left(T_{\mathrm{exp}, i}-T_{\mathrm{cal}, i}\right)^{2}
$$

The calculated mean and maximum deviation results can be found in Table 3.
As it can be seen, the maximum deviation is lower than 1.00 for NRTL, Wilson, and UNIQUAC models and no significant difference is revealed in the accuracy of the models.

The volume and area structural parameters applied in UNIQUAC modeling are demonstrated in Table 4.

It can be determined that ethanol forms a minimal boiling azeotropic mixture with acetal in the investigated concentration range. The calculated binary parameters are presented in Table 5.

The thermodynamic consistency test for ethanol-acetal data was performed according to Herrington's area test for isobaric data. $^{30,34} D_{\mathrm{H}}$ and $J_{\mathrm{H}}$ values are calculated according to the following equations.

$$
\begin{aligned}
& D_{H}=100 \times\left|\frac{\int_{x_{1}=0}^{x_{1}=1} \ln \left(\gamma_{1} / \gamma_{2}\right) \mathrm{dx} x_{1}}{\int_{x_{1}=0}^{x_{1}=1} \mid \ln \left(\gamma_{1} / \gamma_{2}\right) \mathrm{dx} x_{1}}\right| \\
& J_{H}=150 \times \frac{\left|\Delta T_{\max }\right|}{T_{\min }} \\
& D_{H}-J_{H} \leq 10 \%
\end{aligned}
$$

The $D_{\mathrm{H}}$ value was $18.3 \%$ and the $J_{\mathrm{H}}$ value was found to be $9.5 \%$; therefore, $D_{\mathrm{H}}-J_{\mathrm{H}}$ is $8.8 \%$. It can be concluded that the measured data is suitable for application in a flowsheet environment. The elaborated ethanol-acetal binary model can be used for simulation of the ethanol purification column.

Figure 5 shows the optimization of ethanol purification. The red line represents the acetal target concentration in the bottom product, which is $10 \mathrm{ppm}$. Acetaldehyde did not occur in the bottom product in any of the cases. The feed was close to the

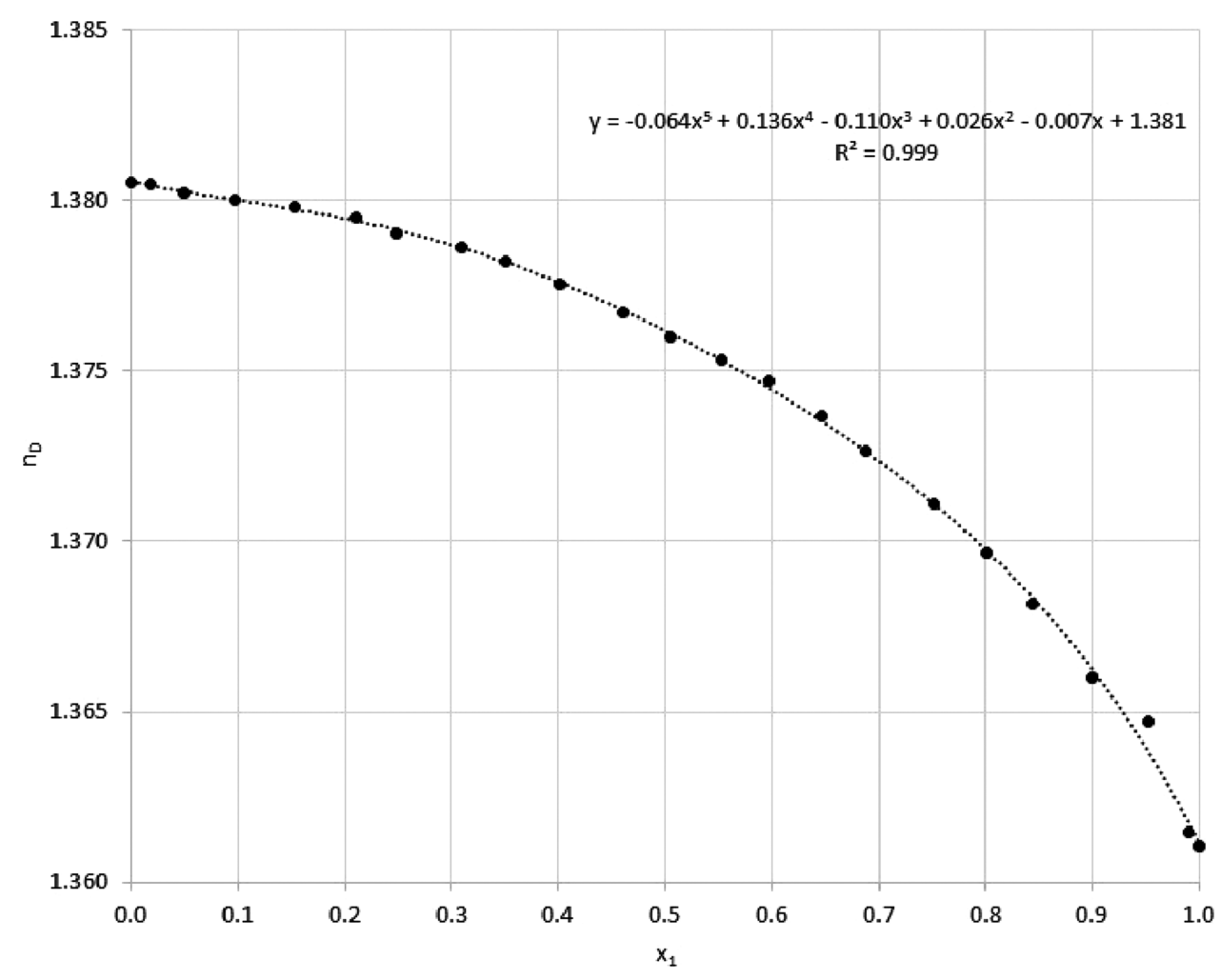

Figure 2. Experimental refractive indexes of the system ethanol (1)-acetal (2) at $\mathrm{T}=293.2 \mathrm{~K}$ (black solid circle) $x_{1}$ : mole fraction of ethanol 
Table 2. VLE Data (T, Temperature; $x$, Liquid Mole Fraction; $y$, Vapor Mole Fraction) of Ethanol (1)-Acetal (2) at $p=101 \mathrm{kPa}{ }^{a}$

\begin{tabular}{|c|c|c|c|c|c|c|c|c|c|c|}
\hline \multirow[b]{3}{*}{$T[\mathrm{~K}]$} & \multirow[b]{3}{*}{$x_{1}$} & \multirow{2}{*}{\multicolumn{2}{|c|}{ rimental data }} & \multirow[b]{3}{*}{$\gamma_{2}$} & \multicolumn{6}{|c|}{ calculated data } \\
\hline & & & & & \multicolumn{2}{|c|}{ NRTL } & \multicolumn{2}{|c|}{ Wilson } & \multicolumn{2}{|c|}{ UNIQUAC } \\
\hline & & $y_{1}$ & $\gamma_{1}$ & & $T[\mathrm{~K}]$ & $y_{1}$ & $T[\mathrm{~K}]$ & $y_{1}$ & $T[\mathrm{~K}]$ & $y_{1}$ \\
\hline 373.19 & 0.0258 & 0.1089 & 2.0077 & 1.0421 & 375.65 & 0.0000 & 375.65 & 0.0000 & 375.65 & 0.0000 \\
\hline 369.12 & 0.0738 & 0.2595 & 2.0294 & 1.1005 & 371.42 & 0.1720 & 371.46 & 0.1706 & 371.45 & 0.1712 \\
\hline 365.85 & 0.1356 & 0.3721 & 1.8188 & 1.1438 & 368.01 & 0.2986 & 368.08 & 0.2966 & 368.04 & 0.2977 \\
\hline 364.98 & 0.1552 & 0.4224 & 1.8107 & 1.0804 & 365.22 & 0.3957 & 365.30 & 0.3932 & 365.24 & 0.3948 \\
\hline 360.86 & 0.2718 & 0.5389 & 1.5094 & 1.2832 & 362.88 & 0.4726 & 362.98 & 0.4696 & 362.89 & 0.4715 \\
\hline 360.23 & 0.2836 & 0.5607 & 1.6563 & 1.2109 & 360.91 & 0.5350 & 361.03 & 0.5315 & 360.92 & 0.5336 \\
\hline 358.67 & 0.3291 & 0.5853 & 1.5045 & 1.2831 & 359.24 & 0.5866 & 359.37 & 0.5828 & 359.25 & 0.5850 \\
\hline 357.12 & 0.3746 & 0.6297 & 1.4735 & 1.3282 & 357.82 & 0.6301 & 357.96 & 0.6261 & 357.83 & 0.6282 \\
\hline 356.32 & 0.4201 & 0.6567 & 1.4045 & 1.3640 & 356.60 & 0.6673 & 356.75 & 0.6633 & 356.62 & 0.6652 \\
\hline 355.23 & 0.4563 & 0.6818 & 1.3916 & 1.3393 & 355.56 & 0.6995 & 355.71 & 0.6957 & 355.58 & 0.6973 \\
\hline 354.34 & 0.5273 & 0.7206 & 1.3197 & 1.4058 & 354.67 & 0.7278 & 354.82 & 0.7245 & 354.69 & 0.7257 \\
\hline 353.87 & 0.5719 & 0.7474 & 1.2702 & 1.4908 & 353.92 & 0.7531 & 354.05 & 0.7505 & 353.93 & 0.7512 \\
\hline 353.12 & 0.6382 & 0.7779 & 1.2003 & 1.5846 & 353.27 & 0.7762 & 353.39 & 0.7743 & 353.29 & 0.7745 \\
\hline 352.64 & 0.6796 & 0.7939 & 1.1741 & 1.7034 & 352.73 & 0.7978 & 352.82 & 0.7968 & 352.73 & 0.7964 \\
\hline 352.12 & 0.7076 & 0.8092 & 1.1501 & 1.7394 & 352.26 & 0.8185 & 352.34 & 0.8184 & 352.26 & 0.8175 \\
\hline 351.56 & 0.7367 & 0.8219 & 1.1359 & 1.8367 & 351.87 & 0.8392 & 351.92 & 0.8399 & 351.86 & 0.8386 \\
\hline 351.23 & 0.7702 & 0.8325 & 1.1188 & 1.8934 & 351.54 & 0.8610 & 351.58 & 0.8622 & 351.53 & 0.8606 \\
\hline 351.11 & 0.8309 & 0.8646 & 1.0862 & 2.1243 & 351.27 & 0.8850 & 351.30 & 0.8865 & 351.26 & 0.8849 \\
\hline 351.01 & 0.8517 & 0.8785 & 1.0769 & 2.1912 & 351.09 & 0.9136 & 351.10 & 0.9148 & 351.08 & 0.9135 \\
\hline 350.99 & 0.9410 & 0.9381 & 1.0528 & 2.5918 & 351.01 & 0.9499 & 351.01 & 0.9504 & 351.00 & 0.9498 \\
\hline 350.95 & 0.8976 & 0.9009 & 1.0644 & 2.3976 & 351.13 & 1.0000 & 351.13 & 1.0000 & 351.13 & 1.0000 \\
\hline 350.91 & 0.9620 & 0.9556 & 1.0534 & 2.8931 & & & & & & \\
\hline
\end{tabular}

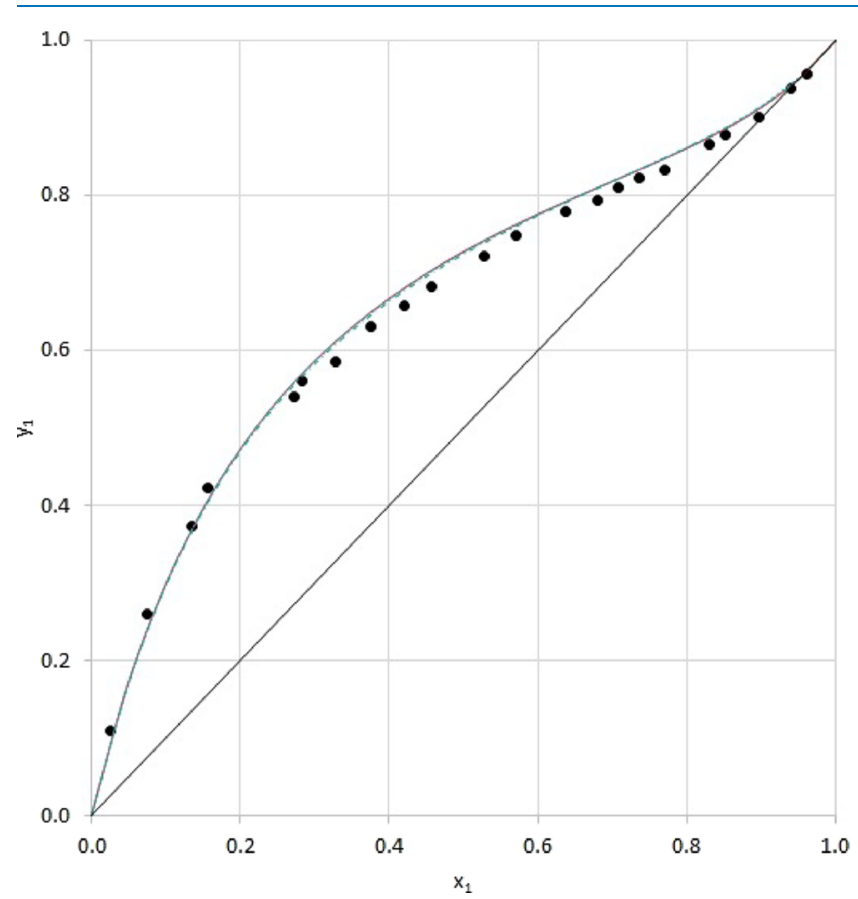

Figure 3. $y-x$ diagram for the ethanol (1)-acetal (2) system at $p=101$ $\mathrm{kPa}$ with experimental data (black solid circle), Wilson (green line), UNIQUAC (blue line), and NRTL (red line) activity coefficient models

boiling point in every case. Studying Figure 5, the following optimized parameters can be determined: 40 theoretical stages, feed into the eighth stage, the reflux ratio is 26 , and column pressure must be kept at $10 \mathrm{kPa}$. The relatively high values can be considered realistic because extreme purity ethanol was the

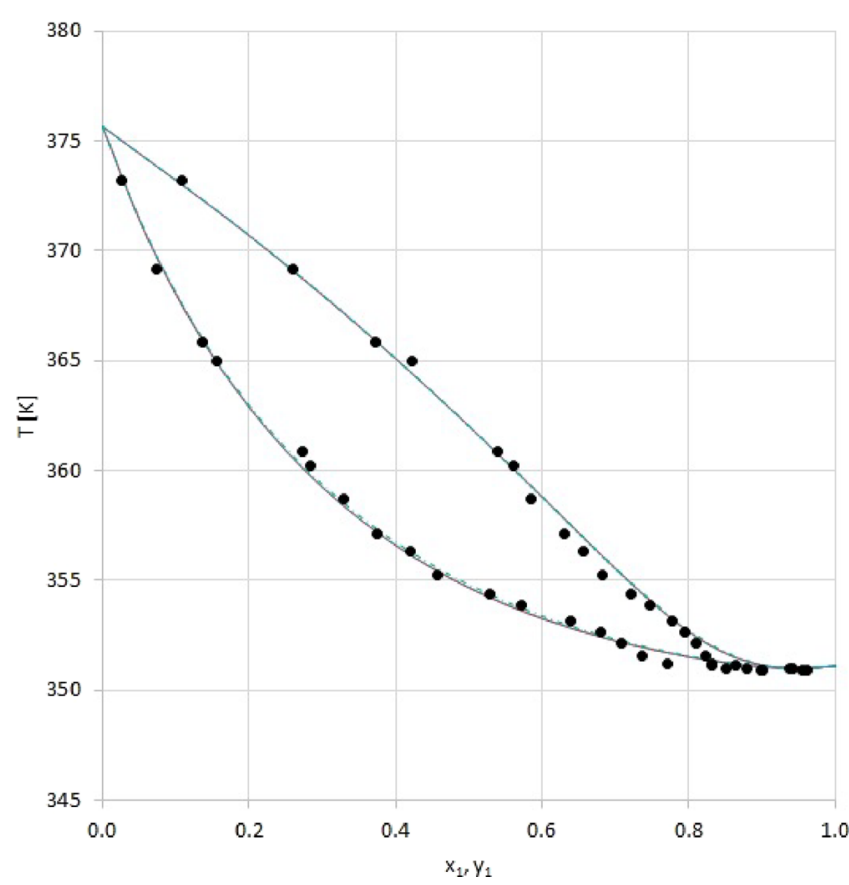

Figure 4. $T-y-x$ diagram for the ethanol (1) - acetal (2) system at $p=$ $101 \mathrm{kPa}$ with experimental data (black solid circle), Wilson (green line), UNIQUAC (blue line), and NRTL (red line) activity coefficient models

goal. It must be mentioned that $10 \mathrm{kPa}$ has to be achieved in feed and column pressure to reach the corresponding acetal concentration in the bottom product. Under a pressure value of $10 \mathrm{kPa}$, it is difficult to keep up the working pressure in the laboratory column apparatus; therefore, computer calculations were not performed below this value. 
Table 3. Accuracy of NRTL, Wilson, and UNIQUAC Models

\begin{tabular}{|c|c|c|c|c|c|c|}
\hline & \multicolumn{2}{|c|}{ NRTL } & \multicolumn{2}{|c|}{ Wilson } & \multicolumn{2}{|c|}{ UNIQUAC } \\
\hline & $T[\mathrm{~K}]$ & $y_{1}$ & $T[\mathrm{~K}]$ & $y_{1}$ & $T[\mathrm{~K}]$ & $y_{1}$ \\
\hline mean deviation & 0.39 & 0.0099 & 0.39 & 0.0102 & 0.34 & 0.0103 \\
\hline max. deviation & 0.92 & 0.0209 & 0.91 & 0.0189 & 0.92 & 0.0221 \\
\hline
\end{tabular}

Table 4. Structural Parameters for Pure Components ( $R$ : Volume Parameter and Q: Area Parameter)

$\begin{array}{cll}\text { parameter } & \text { acetal } & \text { ethanol } \\ R & 4.9868 & 2.1054 \\ Q & 4.332 & 1.972\end{array}$

Table 5. Calculated Binary (Ethanol and Acetal) Interaction Parameters of Wilson $\left(\lambda_{12}, \lambda_{21}\right.$, Adjustable Parameters), NRTL $\left(B_{\mathrm{ij}}, B_{\mathrm{ji}}\right.$, Dimensionless Interaction Parameters; $\boldsymbol{\alpha}$, Constant Characteristic of the Nonrandomness of the Mixture), and UNIQUAC $\left(\Delta U_{\mathrm{ij}}, \Delta U_{\mathrm{ji}}\right.$, Binary Interaction Parameter) Models

\begin{tabular}{|c|c|c|c|c|c|c|}
\hline \multicolumn{3}{|c|}{ NRTL } & \multicolumn{2}{|c|}{ Wilson } & \multicolumn{2}{|c|}{ UNIQUAC } \\
\hline$B_{\mathrm{ij}}$ & $B_{\mathrm{ji}}$ & $\alpha$ & $\lambda_{12}$ & $\lambda_{21}$ & $\Delta U_{\mathrm{ij}}$ & $\Delta U_{\mathrm{ji}}$ \\
\hline 559.08 & -168.65 & 0.296 & 525.002 & 213.742 & 16.25 & 269.9 \\
\hline
\end{tabular}

The reboiler duty value was $2278 \mathrm{MJ} / \mathrm{h}$ in the optimum. Figure 6 shows the influence of reboiler duties (Q-RD) on the acetal concentration of the bottom product (W-Acetal).
The experiments were carried out according to the optimized results of the simulations. The reflux ratio was 26 and the distillate/feed ratio was the same as that of the simulation, $10 \%$. The feed flow rate was $3 \mathrm{~kg} / \mathrm{h}$ in the case of laboratory experiments. The trap flow rate was $0.05 \mathrm{~kg} / \mathrm{h}$, which was analyzed together with the distillate product due to its nearly identical composition. In this evaluation part, the best available results are presented. Table 6 shows the optimized simulation results and their control laboratory measurement results. The simulation verification can be taken with the objective function $\left(\mathrm{OF}_{\text {Distillation }}\right)$, which presents minimized deviation of the simulated and the measured values (see eq 6). ${ }^{35}$

$$
\mathrm{OF}_{\text {Distillation }}=\sum_{i=1}^{n}\left(\frac{D \text { or } W_{\text {Experiment }}-D \text { or } W_{\text {Modeling }}}{D \text { or } W_{\text {Experiment }}}\right)^{2}
$$

The prespecified purification requirements can be achieved in both laboratory and simulation cases as shown in Table 6 . As it can be seen, low objective function values can be achieved due to the accurate assembly of laboratory apparatus. Furthermore, the laboratory experiments justified the accuracy of VLE data, especially ethanol-acetal measurements, which also proved to be valid under vacuum conditions.

\section{CONCLUSIONS}

VLE data for the ethanol-acetal binary system were measured using a modified Gillespie still. Experimental data were
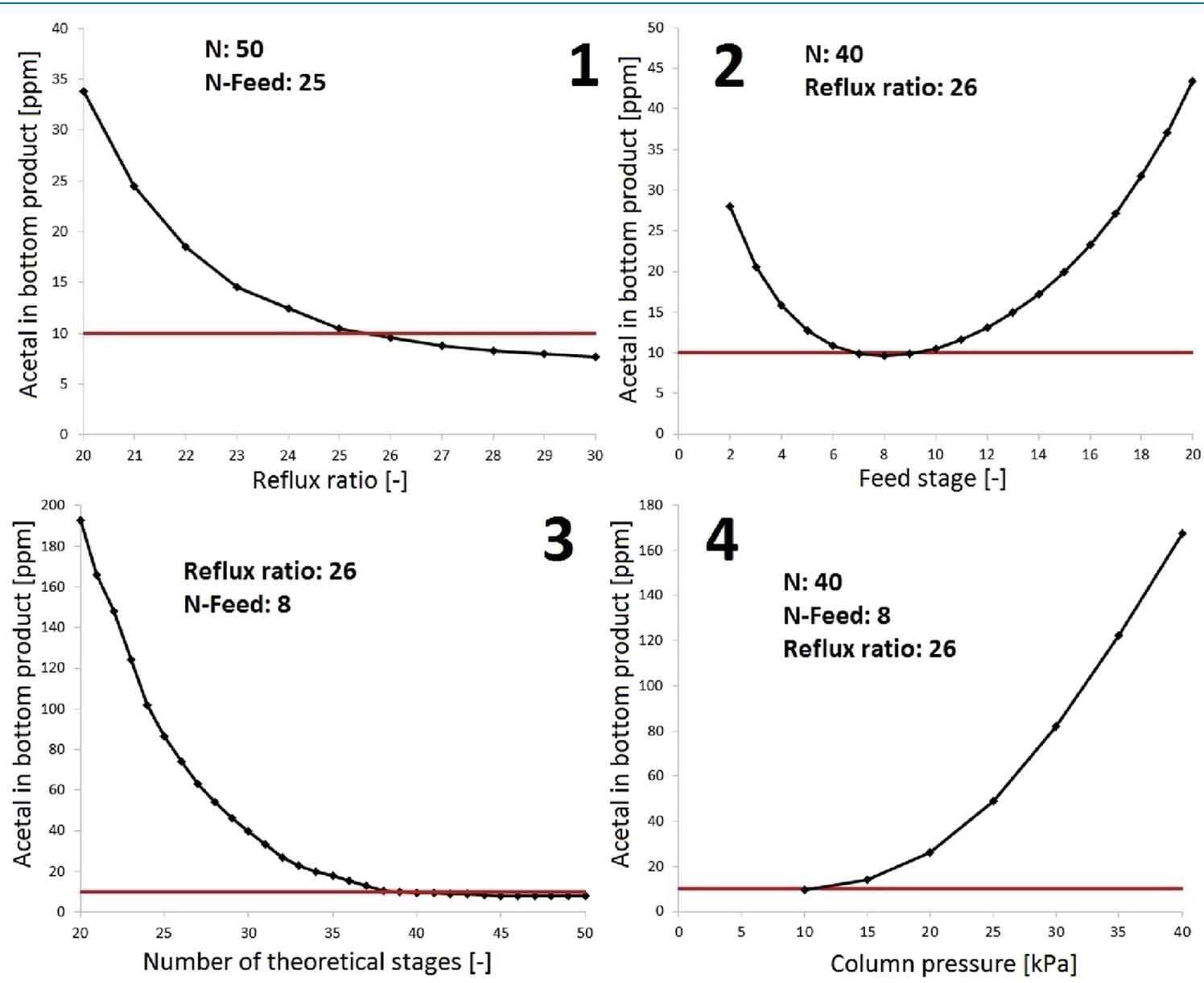

Figure 5. Optimization process of modeling of anhydrous ethanol purification. 

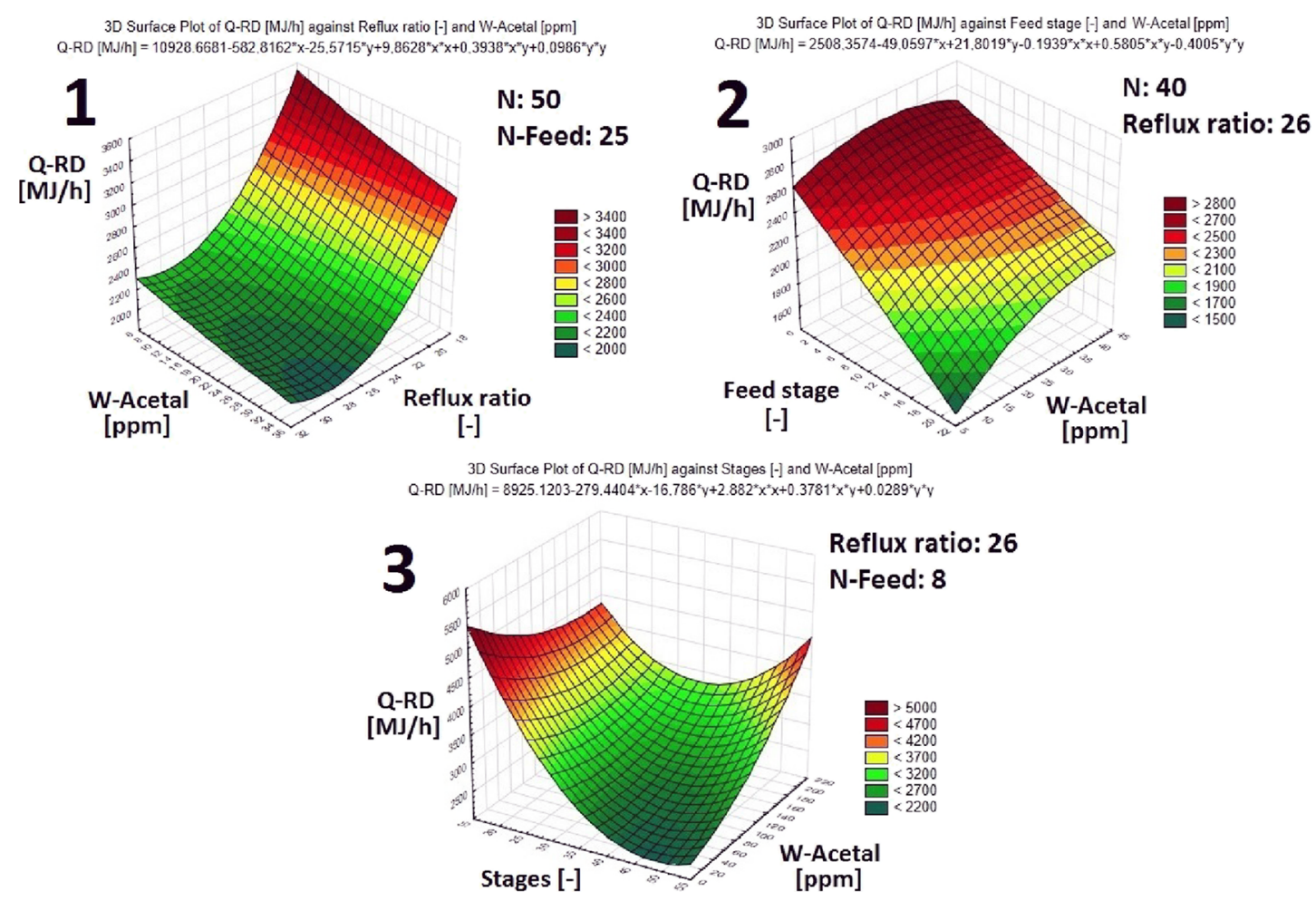

Figure 6. Influence of the reboiler duties [Q-RD $(\mathrm{MJ} / \mathrm{h})]$ and acetal concentration of the bottom product [W-Acetal (ppm)] on the reflux ratio $[-]$ $(1)$, feed stage $[-](2)$, and stages $[-](3)$

Table 6. Comparison of Simulated and Measured Data of the Anhydrous Ethanol Purification Process

\begin{tabular}{|c|c|c|c|c|c|c|c|}
\hline & \multirow[b]{2}{*}{ feed } & \multicolumn{2}{|c|}{ modeling results } & \multicolumn{2}{|c|}{ experimental results } & \multicolumn{2}{|c|}{ OF-distillation } \\
\hline & & distillate & bottom & distillate & bottom & distillate & bottom \\
\hline ethanol $[\mathrm{wt} \%]$ & 99.79 & 98.22 & 99.97 & 98.21 & 99.97 & $3.25 \times 10^{-9}$ & $2.50 \times 10^{-11}$ \\
\hline methanol [ppm] & 63.6 & 635.9 & 0.0 & 623.7 & 0.0 & $3.80 \times 10^{-4}$ & 0 \\
\hline acetal [ppm] & 994.0 & 9853.7 & 9.6 & 9892.4 & 9.5 & $1.53 \times 10^{-5}$ & $8.40 \times 10^{-5}$ \\
\hline ethyl acetate $[\mathrm{ppm}]$ & 41.1 & 410.5 & 0.0 & 402.6 & 0.0 & $3.84 \times 10^{-4}$ & 0 \\
\hline acetaldehyde [ppm] & 278.3 & 2783.0 & 0.0 & 2794.8 & 0.0 & $1.80 \times 10^{-5}$ & 0 \\
\hline diethyl ether [ppm] & 37.8 & 377.8 & 0.0 & 379.0 & 0.0 & $9.77 \times 10^{-6}$ & 0 \\
\hline isobutanol $[\mathrm{ppm}]$ & 210.6 & 0.0 & 234.0 & 0.0 & 235.3 & 0 & $2.74 \times 10^{-5}$ \\
\hline stream $[\mathrm{kg} / \mathrm{h}]$ & 1000 and 3 & 100 & 900 & 0.3 & 2.7 & & \\
\hline temperature $\left[{ }^{\circ} \mathrm{C}\right]$ & 28.5 & 28.1 & 29.1 & 27.9 & 29.2 & $5.14 \times 10^{-5}$ & $1.17 \times 10^{-5}$ \\
\hline pressure $[\mathrm{kPa}]$ & 10 & 10 & 10 & 10 & 9 & & \\
\hline
\end{tabular}

Table 7. Description of Chemicals Applied in This Work (MW: Molecular Weight)

\begin{tabular}{|c|c|c|c|c|c|c|c|}
\hline chemical name & formula & $\mathrm{MW}[\mathrm{g} / \mathrm{mol}]$ & source & initial mole fraction purity & purification method & final mole fraction purity & analysis method \\
\hline ethanol (1) & $\mathrm{C}_{2} \mathrm{H}_{6} \mathrm{O}$ & 46.07 & molar chemicals & 0.9999 & & & $\mathrm{GC}-\mathrm{MS}$ \\
\hline acetal (2) & $\mathrm{C}_{6} \mathrm{H}_{14} \mathrm{O}_{2}$ & 118.17 & sigma-aldrich & 0.9800 & distillation & 0.9995 & $\mathrm{GC}-\mathrm{MS}$ \\
\hline acetaldehyde & $\mathrm{C}_{2} \mathrm{H}_{4} \mathrm{O}$ & 44.05 & sigma-aldrich & 0.9950 & distillation & 0.9999 & GC-MS \\
\hline
\end{tabular}

correlated with Wilson, NRTL, and UNIQUAC models. It was demonstrated that acetal forms a minimal boiling azeotropic mixture with ethanol. The data were applied for the design of an ethanol purification unit. Pharmacopeial quality anhydrous alcohol can be produced with the vacuum distillation method. The pollutant content of the bottom product can be reduced below $300 \mathrm{ppm}$ and for the most important compound, acetal, a value under $10 \mathrm{ppm}$ can be reached. Evaluating the simulated and the experimentally measured data, it can be stated that almost perfect isolation can be guaranteed with the application of the best available laboratory devices. The other conclusion to be drawn is that close to $0 \%$ or to $100 \%$ we land in a dangerous region where modeling becomes more important and special attention needs to be paid to the experimental work and analytics. It must be mentioned that there is consistency between the results of flowsheet simulations, distillation and VLE experiments, respectively.

\section{MATERIALS AND METHODS}

Before the examination of anhydrous ethanol purification, vapor-liquid measurements were performed. The VLE data of acetaldehyde-ethanol is already well known in the literature. ${ }^{29}$ Therefore, this mixture was examined for the correct operation of the VLE still. 
Table 8. Experimental and Literature Refractive Indexes $\left(n_{\mathrm{D}}\right)$ at 293.2 K of Pure Compounds Used and Antoine Constants

\begin{tabular}{llll}
\multicolumn{1}{c}{ property } & ethanol & \multicolumn{1}{c}{ acetal } & acetaldehyde \\
$n_{\mathrm{D}}$ present work & 1.3611 & 1.3805 & 1.3308 \\
$n_{\mathrm{D}}$ literature & 1.3613 & 1.3819 & 1.3316 \\
$n_{\mathrm{D}}$ reference & 37 & 38 & 39 \\
Antoine constants $^{a}$ & & & \\
$\mathrm{~A}$ & 5.24677 & 4.7498 & 3.68639 \\
$\mathrm{~B}$ & 1598.673 & 1573.964 & 822.894 \\
$\mathrm{C}$ & -46.424 & -43.681 & -69.899 \\
$\mathrm{~T}$-min [K] & 292.77 & 250 & 293.4 \\
T-max [K] & 366.63 & 375.3 & 377.5 \\
reference & 40 & 41 & 42,43
\end{tabular}

${ }^{a}$ Antoine constants (bar, K) of ethanol, acetal, and acetaldehyde were calculated by NIST from literature data.

Table 9. Components of the Anhydrous Ethanol Sample with the Boiling Point of Pure Component at $101 \mathrm{kPa}$

\begin{tabular}{llll}
\multicolumn{1}{c}{ substance } & $\begin{array}{c}\text { ppm- } \\
\mathrm{v} / \mathrm{v}\end{array}$ & wt \% & $\begin{array}{c}\text { pure component boiling point } \\
{\left[{ }^{\circ} \mathrm{C}\right]}\end{array}$ \\
ethanol & - & 99.79 & 78.4 \\
methanol & 64 & $8.05 \times 10^{-3}$ & 64.7 \\
acetal & 994 & $1.26 \times 10^{-1}$ & 102.5 \\
ethyl acetate & 41 & $5.20 \times 10^{-3}$ & 77.1 \\
acetaldehyde & 278 & $3.53 \times 10^{-2}$ & 20.2 \\
diethyl ether & 38 & $4.79 \times 10^{-3}$ & 34.6 \\
isobutanol & 211 & $2.67 \times 10^{-2}$ & 108.0
\end{tabular}

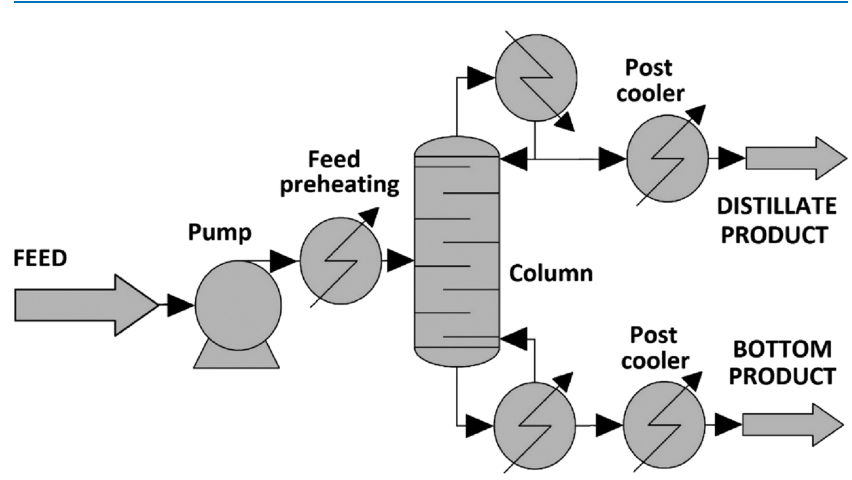

Figure 7. Flowsheet of anhydrous alcohol purification.

The properties of the commercially available chemicals used in VLE examination are introduced in Table 7. Ethanol was applied without further purification. Acetal and acetaldehyde were purified by vacuum distillation at a pressure of $27 \mathrm{kPa}$.

The VLE still is a modified Gillespie apparatus. An amount of about $100 \mathrm{~mL}$ of the appropriate mixture was added to the liquid container at the site of the top valve. For the heating of the mixture, an electric resistance wire was used, folded around the boiler tube. Through the Cottrell-pump, the vapor-liquid mixture was lifted into the thermometer well. Subsequently, the phases were directed into the equilibrium chamber, where their separation could occur, at an equilibrium state. The condensation of the vapor phase took place on the surface of the chamber and in the condenser, then the resulting condensate was transferred to the vapor sampler. The sample originating from the liquid phase was obtained at the site of the liquid sampler. For temperature measurement, a VWR Traceable Digital Thermometer (China) was used (223-573 K), presenting an uncertainty of $0.1 \mathrm{~K}$. As for atmospheric pressure,

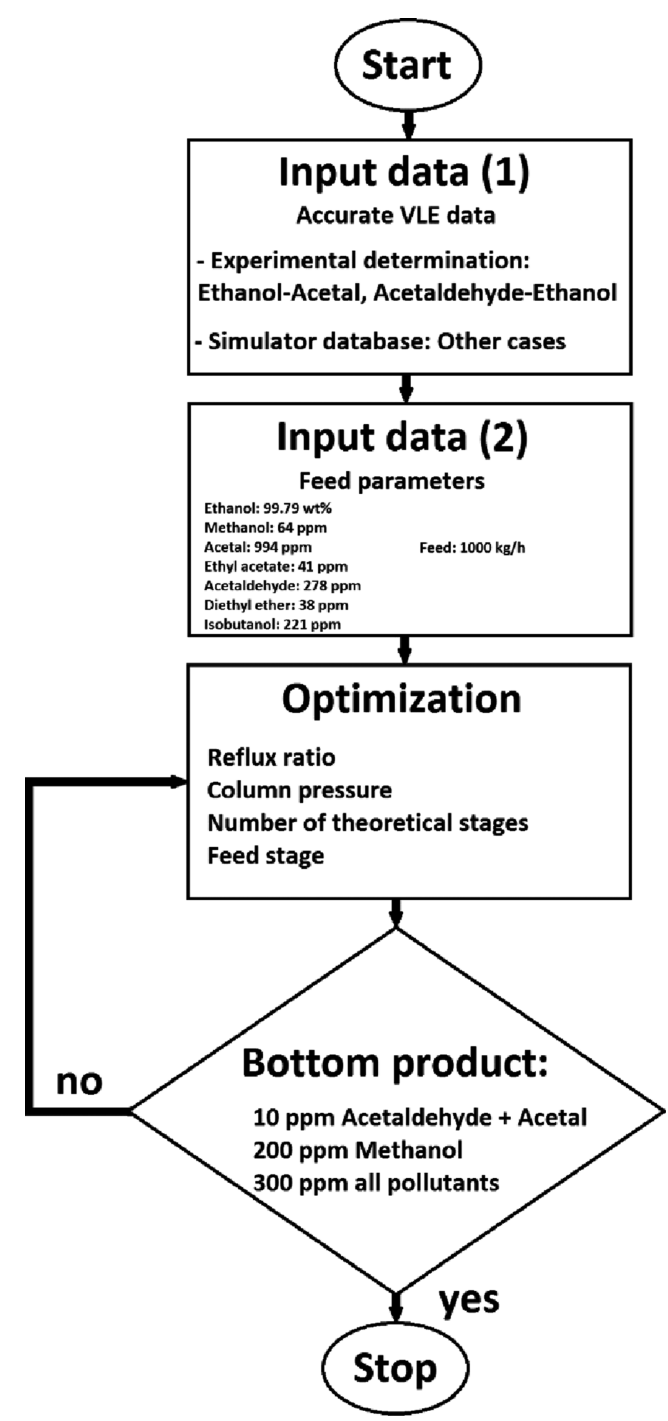

Figure 8. Flowchart of the optimization process of anhydrous alcohol purification.

the accuracy of the measurement was $1 \mathrm{kPa}{ }^{36}$ The atmospheric pressure was measured by a VACUUBRAND PC2003 VARIO (China) vacuum pump.

Refractive indexes were determined for the analysis of the equilibrium samples, three replications were applied. In addition, gas chromatography analysis was performed for certain equilibrium and calibration samples as a validation for the refractometric method. ${ }^{36}$ A Carl Zeiss Abbe Refractometer (Type G) was applied for the analysis of refractive indexes. The accuracy of the refractometer was 0.0001 at $293.2 \mathrm{~K}$, according to the manufacturer. Literature and experimental refractive indexes and Antoine constants of the used chemicals are listed in Table 8 . As it can be seen, the experimental refractive indexes show good agreement with the literature data.

Table 9 contains the main compounds of the raw anhydrous ethanol sample.

The main purification requirements for the composition of pharmacopeial quality anhydrous alcohol are the following: 200 ppm in methanol, $10 \mathrm{ppm}$ in acetaldehyde + acetal, $2 \mathrm{ppm}$ in benzene, and $300 \mathrm{ppm}$ in all pollutants. ${ }^{13}$ It can be seen that more types of substances are above the prescribed composition. 


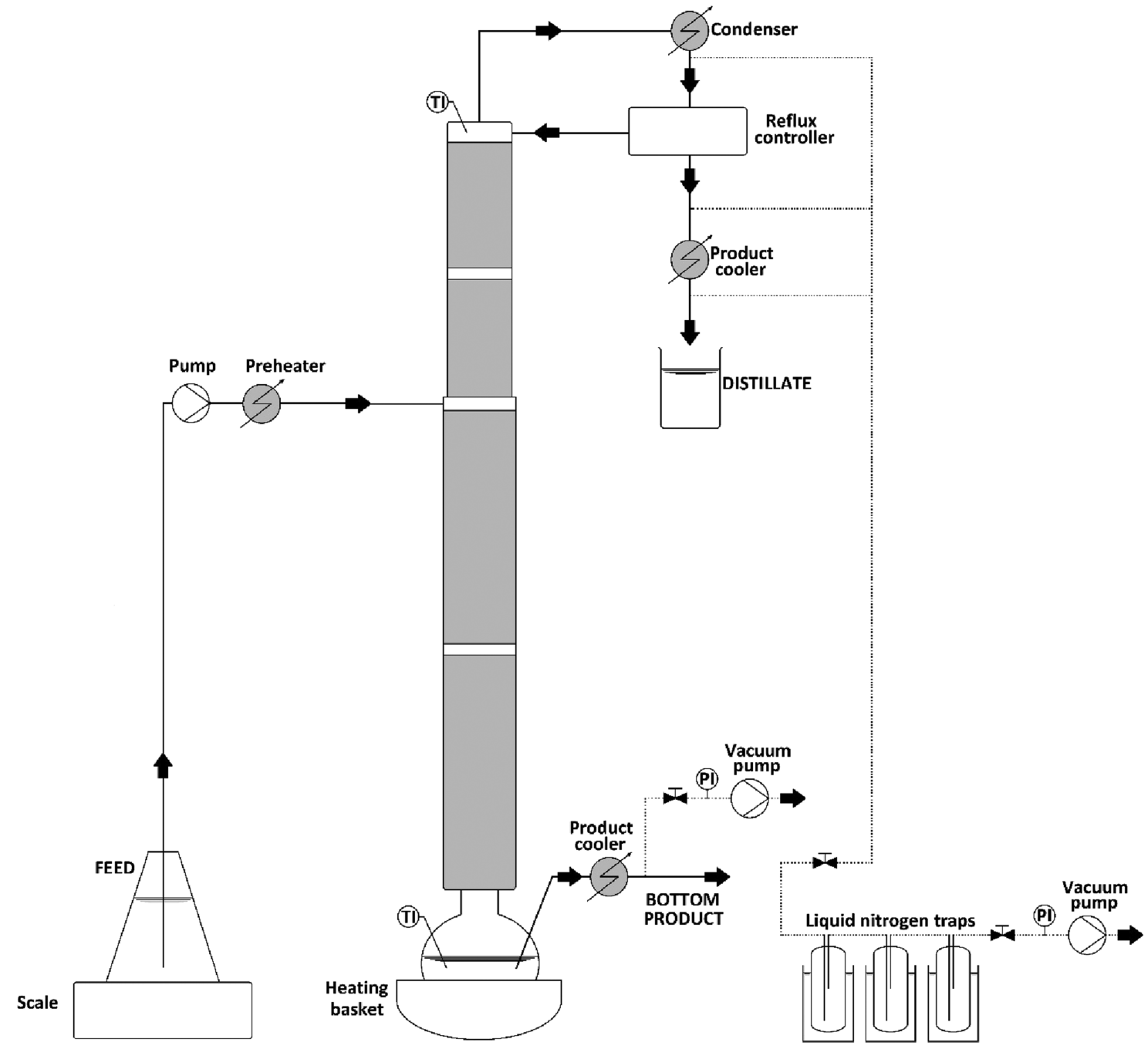

Figure 9. Laboratory demonstrative column for alcohol purification.

Distillation can be performed in discontinuous (batch) and continuous mode. ${ }^{44-46}$ In the present study, the amount to be processed was relatively large $(1000 \mathrm{~kg} / \mathrm{h})$ so continuous operation was recommended. The actual task was to remove polluting compounds and therefore to achieve a high-quality product. According to basic unit operation knowledge, a distillation column with a stripping section should be applied. ${ }^{47}$ Therefore, considering the data in Table 9, it can be estimated in advance that the polluting compounds' removal results mainly in the distillate product and the bottom product contains the pharmacopeial anhydrous alcohol.

At first, flowsheeting simulations were carried out with the ChemCAD 7.1.5 program to get a comprehensive overview about the system and find promising alternatives. The optimal reflux ratio (thereby the distillate and bottom flow rates), column pressure, number of theoretical stages, feed stage, and heating and cooling requirements were also determined with the dynamic programming optimization method. ${ }^{48-50}$ The investigated ethanol sample is considered highly nonideal, because it has more azeotropic binary pairs. As an equilibrium model for the calculation of highly nonideal vapor-liquid equilibria, the UNIQUAC method was applied. ${ }^{51-54}$ Considering the vaporliquid equilibria, that is, our modeling results obtained with ChemCAD, the separation of the ethanol sample can be performed significantly better if vacuum distillation is applied. Figure 7 shows the flowsheet used for modeling the distillation.

Figure 8 summarizes the optimization process of anhydrous alcohol purification.

The modeling results were tested in a laboratory, under experimental conditions. The main parameters of the experimental column were the following: $1.5 \mathrm{~m}$ high and internal diameters of $25 \mathrm{~mm}$ (rectifying section) and $20 \mathrm{~mm}$ (stripping section) with Sulzer EX structured packing (see Figure 9). The column had 40 theoretical stages, according to the measurement carried out with an ethanol-water binary mixture. The feed was preheated and it was pumped into the eighth stage of the column. The column heating was controlled with a heating basket $(300 \mathrm{~W})$. The vacuum was maintained with a VACUUBRAND PC2003 VARIO vacuum pump and kept at $10 \mathrm{kPa}$. Another vacuum pump was also used for bottom product removal and kept at $9 \mathrm{kPa}$. The distillation apparatus was collected in three traps connected in series and cooled with liquid nitrogen to prevent the evaporation and loss of the distillate product. The reflux ratio was maintained with a Bertolt reflux controller.

As a startup procedure of the experiments, batch distillation was first carried out to obtain a relatively pure liquid satisfying the purity prescriptions in the reboiler. ${ }^{13}$ Afterward, continuous 
mode was used until a steady-state (constant output flows and temperatures) operation was achieved.

The content of the feed $(F)$, distillate $(D)$, bottom product $(W)$, and traps were measured with a Shimadzu GC2010Plus + AOC-20 autosampler gas chromatograph with a ID-BP1 $(60 \mathrm{~m}$ $\times 0.32 \mathrm{~mm}, 1.0 \mu \mathrm{m}$ ) column using helium as the carrier gas. The column temperature was kept at constant $60{ }^{\circ} \mathrm{C}$ while the injector was thermostated to $250{ }^{\circ} \mathrm{C}$ and $\mathrm{MS}$ ion source temperature was set to $250^{\circ} \mathrm{C}$. Pressure of the helium carrier gas (with 5.0 purity) was kept at $90 \mathrm{kPa}$. The results were the average of three analyses in the analytical method. ${ }^{55}$

\section{ASSOCIATED CONTENT}

\section{(s) Supporting Information}

The Supporting Information is available free of charge at https://pubs.acs.org/doi/10.1021/acsomega.0c04750.

Experimental equilibrium data and $y-x$ diagram and $T-$ $y-x$ diagram for the acetaldehyde (1)-ethanol (2) system (PDF)

\section{AUTHOR INFORMATION}

\section{Corresponding Author}

Andras Jozsef Toth - Department of Chemical and Environmental Process Engineering, Budapest University of Technology and Economics, Budapest H-1111, Hungary;

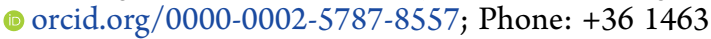

1494; Email: andrasjozseftoth@edu.bme.hu

\section{Authors}

Eniko Haaz - Department of Chemical and Environmental Process Engineering, Budapest University of Technology and Economics, Budapest H-1111, Hungary

Daniel Fozer - Department of Chemical and Environmental Process Engineering, Budapest University of Technology and Economics, Budapest H-1111, Hungary

Complete contact information is available at:

https://pubs.acs.org/10.1021/acsomega.0c04750

\section{Notes}

The authors declare no competing financial interest.

\section{ACKNOWLEDGMENTS}

This publication was supported by the János Bolyai Research Scholarship of the Hungarian Academy of Sciences, ÚNKP-204-II-BME-296 New National Excellence Program of the Ministry for Innovation and Technology, NTP-NFTÖ-20-B0095 National Talent Program of the Cabinet Office of the Prime Minister, OTKA 128543 and 131586. The research reported in this paper and carried out at the Budapest University of Technology and Economics has been supported by the National Research Development and Innovation Fund (TKP2020 National Challenges Subprogram, Grant No. BME-NC) based on the charter of bolster issued by the National Research Development and Innovation Office under the auspices of the Ministry for Innovation and Technology.

\section{ABBREVIATION}

\section{Nomenclature}

$B_{\mathrm{ij}}, B_{\mathrm{ji}} \quad$ Dimensionless interaction parameters (NRTL model)

D Distillate product

$D_{\mathrm{H}} \quad$ Parameter for Herington consistency test

$\begin{array}{ll}F & \text { Feed } \\ J_{\mathrm{H}} & \text { Parameter for Herington consistency test } \\ \mathrm{MW} & \text { Molecular weight } \\ N & \text { Number of theoretical stages } \\ n_{\mathrm{D}} & \text { Refractive index } \\ \mathrm{OF} & \text { Objective function } \\ p & \text { Pressure }[\mathrm{kPa}] \\ p_{\mathrm{i}}^{*} & \text { Partial pressure of component } i[\mathrm{~Pa}] \\ Q & \text { Area parameter }(\mathrm{UNIQUAC} \text { model) } \\ \mathrm{Q}-\mathrm{RD} & \text { Reboiler duty }[\mathrm{MJ} / \mathrm{h}] \\ R & \text { Volume parameter (UNIQUAC model) } \\ T & \left.\text { Temperature [ }{ }^{\circ} \mathrm{C} \text { K }\right] \\ \Delta U_{\mathrm{ij}}, \Delta U_{\mathrm{ji}} & \text { Binary interaction parameter (UNIQUAC model) } \\ \mathrm{VLE} & \text { Vapor-Liquid Equilibrium } \\ W & \text { Bottom product } \\ \text { wt } \% & \text { Weight percent } \\ x & \text { Liquid mole fraction } \\ y & \text { Vapor mole fraction }\end{array}$

\section{Greek letters}

$\alpha \quad$ Constant characteristic of the nonrandomness of the mixture (NRTL model)

$\gamma_{i} \quad$ Activity coefficient

$\lambda_{12}, \lambda_{21}$ Adjustable parameters (Wilson model)

\section{REFERENCES}

(1) Batista, F. R. M.; Follegatti-Romero, L. A.; Meirelles, A. J. A. A new distillation plant for neutral alcohol production. Sep. Purif. Technol. 2013, 118, 784-793.

(2) Ravagnani, M. A. S. S.; Reis, M. H. M.; Filho, R. M.; Wolf-Maciel, M. R. Anhydrous ethanol production by extractive distillation: A solvent case study. Process Saf. Environ. Prot. 2010, 88, 67-73.

(3) Álvarez, V. H.; Alijó, P.; Serrão, D.; Filho, R. M.; Aznar, M.; Mattedi, S. Production of Anhydrous Ethanol by Extractive Distillation of Diluted Alcoholic Solutions with Ionic Liquids. In Comput.-Aided Chem. Eng de Brito Alves, R. M.; do Nascimento, C. A. O.; Biscaia, E. C., Eds. Elsevier: 2009; 27, 1137-1142.

(4) Hoch, P. M.; Espinosa, J. Optimisation of a bio-ethanol purification process using conceptual design and simulation tools. In Comput.-Aided Chem. Eng., Braunschweig, B.; Joulia, X., Eds. Elsevier: 2008, 25, 235-240.

(5) Shenoy, A. U.; Shenoy, U. V. Designing optimal bioethanol networks with purification for integrated biorefineries. Energy Convers. Manage. 2014, 88, 1271-1282.

(6) Kumar, S.; Singh, N.; Prasad, R. Anhydrous ethanol: A renewable source of energy. Renew. Sust. Energ. Rev. 2010, 14, 1830-1844.

(7) Pinto, V. S. Use of $1 \mathrm{H}$ nuclear magnetic resonance and chemometrics to detect the percentage of ethanol anhydrous in Brazilian type C premium gasoline. Fuel 2020, 276, 118015.

(8) Gabriel, K.; Santos, M. M.; Adriano, J.; Marques, J.; Lemos, M.; Muachia, A.; Barros, A. A. C. Anhydrous bio-ethanol produced from Elaeis Guineensis palm wine for use as a biodiesel feedstock. S. Afr. J. Chem. Eng. 2019, 29, 10-16.

(9) Loy, Y. Y.; Lee, X. L.; Rangaiah, G. P. Bioethanol recovery and purification using extractive dividing-wall column and pressure swing adsorption: An economic comparison after heat integration and optimization. Sep. Purif. Technol. 2015, 149, 413-427.

(10) Kaymak, D. B. Design and Control of a Separation Process for Bioethanol Purification by Reactive Distillation. In Comput.-Aided Chem. Eng., Espuña, A.; Graells, M.; Puigjaner, L., Eds. Elsevier: 2017; 40, 1075-1080.

(11) HealthCare, E. D. F. T. Q. O. M. European Pharmacopoeia (Ph. Eur.). 10th edition; Council of Europe: 2019.

(12) Snodin, D. J.; McCrossen, S. D. Guidelines and pharmacopoeial standards for pharmaceutical impurities: Overview and critical assessment. Regul. Toxicol. Pharmacol. 2012, 63, 298-312. 
(13) Paál, T.; Szalai, H.; Nagy, A.; Haraszti, C.; Boldizsár, I. Pharmacopoea Hungarica. VIII. edition; Medicina: Budapest, 2004.

(14) Zea, L.; Serratosa, M. P.; Mérida, J.; Moyano, L. Acetaldehyde as Key Compound for the Authenticity of Sherry Wines: A Study Covering 5 Decades. Compr. Rev. Food Sci. Food Saf. 2015, 14, 681693.

(15) Maarse, H. Volatile Compounds in Foods and Beverages. Taylor \& Francis: New York, 1991.

(16) Boennhoff, K. 1,1-Diethoxyethane as Diesel Fuel. DE Patent No. 2,911,411, 1980

(17) Boennhoff, K. Method for Enhancing the Ignition Performance of Dialkoxyalkanes Used as Diesel Fuel, in Particular 1,1-Diethoxyethane. DE Patent No. 3,136,030, 1983.

(18) Golubkov, A.; Golubkov, I. Motor Fuel for Diesel, Gas-Turbine and Turbojet Engines. U.S. Patent No. 02/0026744 A1, 2002.

(19) Silva, V. M. T. M.; Rodrigues, A. E. Novel process for diethylacetal synthesis. AIChE J. 2005, 51, 2752-2768.

(20) Bramwyche, P. L.; Mudgan, M.; Stanley, H. M. Manufacture of Diethyl Acetal. U.S Patent No. 2519 540, 1950.

(21) Petersen, M. L. Process for the Production of Liquid Acetals. U.S. Patent No. 4024 159, 1977.

(22) Capeletti, M. a. R.; Balzano, L.; de la Puente, G.; Laborde, M.; Sedran, U. Synthesis of acetal (1,1-diethoxyethane) from ethanol and acetaldehyde over acidic catalysts. Appl. Catal., A 2000, 198, L1-L4.

(23) Kohlpaintner, C.; Schulte, M.; Falbe, J.; Lappe, P.; Weber, J. Ullmann's Encyclopedia of Industrial Chemistry. 7th edition; Wiley-VCH Verlag GmbH \& Co. KGaA.: Germany, 2016.

(24) He, X.; Liu, H. Efficient synthesis of 1,1-diethoxyethane via sequential ethanol reactions on silica-supported copper and $\mathrm{H}-\mathrm{Y}$ zeolite catalysts. Catal. Today 2014, 233, 133-139.

(25) Silva, V. M. T. M.; Pereira, C. S. M.; Rodrigues, A. E.; Verevkin, S. P.; Emel'yanenko, V. N.; Garist, I. V.; Gmehling, J. Experimental and Theoretical Study of Chemical Equilibria in the Reactive Systems of Acetals Synthesis. Ind. Eng. Chem. Res. 2012, 51, 12723-12729.

(26) Gomez, M. F.; Arrúa, L. A.; Abello, M. C. Synthesis of 1,1diethoxyethane using a continuous flow reactor: catalyst deactivation and effect of feed purity and of solvent addition. J. Chem. Technol. Biotechnol. 2004, 79, 391-396.

(27) Ionescu, I.; Cioroianu, D.; Savescu, V. Liquid-vapor-equilibrium data in the binary-systems made up of ethanol, i-propanol and acetaldehyde diethylacetate. Rev. Chim. 1994, 45, 803-807.

(28) Kim, Y.; Sapei, E.; Keskinen, K. I.; Aittamaa, J. Vapor-Liquid Equilibrium for Binary Systems of 2-Propanol + 1,1-Diethoxyethane at $353 \mathrm{~K}$, Ethyl Ethanoate + 1,1-Diethoxyethane at $348 \mathrm{~K}$, and 2Propanone + 1,1-Diethoxyethane at 328 K. J. Chem. Eng. Data 2005, 50, $364-368$.

(29) Gmehling, J.; Onken, U. Vapor-Liquid Equilibrium Data Collection: Aqueous-Organic Systems. DECHEMA: Frankfurt/Main, Germany, 1977.

(30) Herington, E. F. G. A thermodynamic test for the internal consistency of experimental data on volatility ratios. Nature 1947, 160, 610-611.

(31) Wisniak, J. The Herington test for thermodynamic consistency. Ind. Eng. Chem. Res. 1994, 33, 177-180.

(32) Herington, E. F. G. Symmetrical-area tests for the consistency of vapour-liquid equilibrium data. I. Isothermal data. J. Appl. Chem. 1968, $18,285-291$.

(33) Miklós, D.; Kemény, S.; Almásy, G.; Kollár-Hunek, K. Thermodynamic consistency of data banks. Fluid Phase Equilib. 1995, $110,89-113$.

(34) Havasi, D.; Mizsey, P.; Mika, L. T. Vapor-Liquid Equilibrium Study of the Gamma-Valerolactone-Water Binary System. J. Chem. Eng. Data 2016, 61, 1502-1508.

(35) Toth, A. J.; Haaz, E.; Nagy, T.; Tarjani, A. J.; Fozer, D.; Andre, A.; Valentinyi, N.; Mizsey, P. Novel method for the removal of organic halogens from process wastewaters enabling water reuse. Desalin. Water Treat. 2018, 130, 54-62.

(36) Havasi, D.; Pátzay, G.; Kolarovszki, Z.; Mika, L. T. Isobaric Vapor-Liquid Equilibria for Binary Mixtures of $\gamma$-Valerolactone +
Methanol, Ethanol, and 2-Propanol. J. Chem. Eng. Data 2016, 61, 3326-3333.

(37) Rheims, J.; Köser, J.; Wriedt, T. Refractive-index measurements in the near-IR using an Abbe refractometer. Meas. Sci. Technol. 1997, 8, 601-605.

(38) O’Neil, M. J.; Heckelman, P. E.; Dobbelaar, P. H.; Roman, K. J.; Kenny, C. M.; Karaffa, L. S. The Merck Index: An Encyclopedia of Chemicals, Drugs, and Biologicals; Royal Society of Chemistry: 2013.

(39) http://www.raeco.com/training/refractive-index-values.htm.

(40) Ambrose, D.; Sprake, C. H. S. Thermodynamic properties of organic oxygen compounds XXV. Vapour pressures and normal boiling temperatures of aliphatic alcohols. J. Chem. Thermodyn. 1970, 2, 631645

(41) Stull, D. R. Vapor Pressure of Pure Substances. Organic and Inorganic Compounds. Ind. Eng. Chem. 1947, 39, 517-540.

(42) Bull, S. S.; Seregrennaja, I. I.; Tsherbakora, P. R. Isothermic Equilibrium of Liquid-Steam in System Water-Acetoaldehyde. Khim. Prom. (Moscow) 1963, 7, 507-509.

(43) Coles, K. F.; Popper, F. Vapor-Liquid Equilibria. Ethylene Oxide - Acetaldehyde and Ethylene Oxide - Water Systems. Ind. Eng. Chem. 1950, 42, 1434-1438.

(44) Koczka, K.; Mizsey, P. New area for distillation: Wastewater treatment. Period. Polytech., Chem. Eng. 2010, 54, 41-45.

(45) Tóth, A. J.; Gergely, F.; Mizsey, P. Physicochemical treatment of pharmaceutical process wastewater: Distillation and membrane processes. Period. Polytech., Chem. Eng. 2011, 55, 59-67.

(46) Mizsey, P.; Tóth, A. J. Application of the principles of industrial ecology for the treatment of process waste waters with physicochemical tools. Industrial Ecology 2012, 1, 101-126.

(47) Cséfalvay, E.; Deák, A.; Farkas, T.; Hanák, L.; Mika, L. T.; Mizsey, P.; Sawinsky, J.; Simándi, B.; Szánya, T.; Székely, E.; Vágó, E. Chemical Unit Operations II; Typotex Kiadó: Budapest, 2011.

(48) Toth, A. J. Comprehensive evaluation and comparison of advanced separation methods on the separation of ethyl acetateethanol-water highly non-ideal mixture. Sep. Purif. Technol. 2019, 224, 490-508.

(49) Haaz, E.; Toth, A. J. Methanol dehydration with pervaporation: Experiments and modelling. Sep. Purif. Technol. 2018, 205, 121-129.

(50) Edgar, T. F.; Himmelblau, D. M.; Lasdon, L. S. Optimization of chemical processes; McGraw-Hill: Michigan, USA, 2001.

(51) Wiśniewska-Goclowska, B.; Malanowski, S. X. K. A new modification of the UNIQUAC equation including temperature dependent parameters. Fluid Phase Equilib. 2001, 180, 103-113.

(52) Klamt, A.; Krooshof, G. J. P.; Taylor, R. COSMOSPACE: Alternative to conventional activity-coefficient models. AIChE J. 2002, $48,2332-2349$.

(53) Egner, K.; Gaube, J.; Pfennig, A. GEQUAC, an excess Gibbs energy model describing associating and nonassociating liquid mixtures by a new model concept for functional groups. Fluid Phase Equilib. 1999, 158-160, 381-389.

(54) Abrams, D. S.; Prausnitz, J. M. Statistical Thermodynamics of Liquid Mixtures: A New Expression for the Excess Gibbs Energy of Partly or Completely Miscible Systems. AIChE J. 1975, 21, 116-128.

(55) Valentinyi, N.; Andre, A.; Haaz, E.; Fozer, D.; Toth, A. J.; Nagy, T.; Mizsey, P. Experimental investigation and modeling of the separation of ternary mixtures by hydrophilic pervaporation. Sep. Sci. Technol. 2020, 55, 601-617. 